\title{
Effect of in ovo feeding of folic acid on the folate metabolism, immune function and epigenetic modification of immune effector molecules of broiler
}

\author{
Shizhao Li†, Lihui Zhi†, Yanli Liu, Jing Shen, Lei Liu, Junhu Yao* and Xiaojun Yang* \\ College of Animal Science and Technology, Northwest AEF University, Yangling, Shaanxi 712100, People's Republic of China \\ (Submitted 5 March 2015 - Final revision received 16 September 2015 - Accepted 15 October 2015 - First published online 20 November 2015)
}

\section{Abstract}

This study was conducted to investigate the effect of in ovo feeding (IOF) of folic acid on the folate metabolism, immune function and the involved epigenetic modification of broilers. A total of 400 (Cobb) hatching eggs were randomly divided into four groups (0, 50, 100 and $150 \mu \mathrm{g}$ injection of folic acid at embryonic age $11 \mathrm{~d}$ ), and chicks hatched from each treatment were randomly divided into six replicates with 12 broilers/replicate after incubation. The results indicated that, in ovo, 100- and 150- $\mu \mathrm{g}$ folic acid injections improved the hatchability. The average daily gain and feed conversion ratio increased in the 150- $\mu$ g group during the late growth stage. Simultaneously, in the 100- and $150-\mu \mathrm{g}$ groups, an increase was observed in hepatic folate content and the expression of methylenetetrahydrofolate reductase (d1 and 42) and methionine synthase reductase (d21). IgG and IgM concentrations, as well as plasma lysozyme activity of broilers, showed a marked increase along with increasing folic acid levels. The splenic expression levels of $I L-2$ and $I L-4$ were up-regulated, whereas that of $I L-6$ was down-regulated, in the 100- and 150- $\mu$ g folic acid treatment groups. In addition, histone methylation in $I L-2$ and $I L-4$ promoters exhibited an enrichment of $\mathrm{H} 3 \mathrm{~K} 4 \mathrm{~m} 2$ but a loss of $\mathrm{H} 3 \mathrm{~K} 9 \mathrm{me} 2$ with the increased amount of folic acid additive. In contrast, a decrease in $\mathrm{H} 3 \mathrm{~K} 4 \mathrm{~m} 2$ and an increase in $\mathrm{H} 3 \mathrm{~K} 9 \mathrm{me} 2$ were observed in the $I L-6$ promoter in folic acid treatments. Furthermore, in ovo, the $150-\mu \mathrm{g}$ folic acid injection improved the chromatin tightness of the $I L-2$ and $I L-4$ promoter regions. Our findings suggest that IOF of $150 \mu \mathrm{g}$ of folic acid can improve the growth performance and folate metabolism of broilers, and enhance the relationship between immune function and epigenetic regulation of immune genes, which are involved with the alterations in chromatin conformation and histone methylation in their promoters.

Key words: Folic acid: Folate metabolism: Immune function: Epigenetic modifications: Broilers

It is critical for the establishment of the epigenome that during gametogenesis and embryogenesis the epigenome experience elimination and reconstruction twice, respectively ${ }^{(1)}$. Consequently, these two periods, which are vulnerable to the environment (such as nutrition, climate and so on), are the focus of epigenetics studies ${ }^{(2,3)}$. Unlike in mammals, in poultry, embryonic development is mainly separated from the matrix. It is therefore difficult to estimate the effect of nutrients on embryogenesis if nutrients exhibit little or no accumulation in eggs. Currently, in ovo feeding (IOF) is gradually operational ${ }^{(4,5)}$ and it can thus be used to evaluate the effect of specific nutrients on epigenome reprogramming, providing an effective approach to the study of nutri-epigenetics.

Folic acid, a water-soluble B-complex vitamin, also known as pteroylglutamic acid, has a critical role in one-carbon metabolism ${ }^{(6,7)}$. Similarly, folic acid is a central co-enzyme for both DNA methylation and DNA synthesis ${ }^{(8)}$. Methylenetetrahydrofolate reductase (MTHFR; EC 1.5.1.20), a key enzyme in folate metabolism, has a key role in both biological methylation and nucleotide synthesis, balancing these two pathways to preserve normal homoeostasis ${ }^{(7,9)}$. In addition, methionine synthase reductase (MTRR), another pivotal enzyme, is essential for folate and homocysteine metabolism ${ }^{(10)}$.

As a methyl group, folate functions as a ground substance for the formation of methionine, which can be converted to $S$-adenosylmethionine $(\mathrm{SAM})^{(8)}$. In the methionine metabolic cycle, SAM is further converted to $S$-adenosylhomocysteine, thereby donating the methyl group for DNA and protein methylation, and finally changing chromatin conformation ${ }^{(2)}$. Consequently, folate supplementation may modulate gene expression by modifying epigenetic marks such as histone methylation and chromatin conformation.

Folate insufficiency is associated with the clinical syndrome including CVD and intra-uterine growth retardation ${ }^{(11,12)}$, whereas folate supplementation may result in decreased abnormal embryologic development by increasing fetal folate concentrations and supporting normal embryonic DNA synthesis during gestation $^{(13)}$. Folate, as a methyl donor, is able to reverse the epigenetic marks and thereby recover the metabolic disorders in offspring caused by prenatal or neonatal

Abbreviations: BW, body weight; IOF, in ovo feeding; MTHFR, methylenetetrahydrofolate reductase; MTRR, methionine synthase reductase.

* Corresponding authors: X. J. Yang, fax +8629 87092341, email yangxj@nwsuaf.edu.cn; J. Yao, yaojunhu2004@sohu.com

$\dagger$ These authors contributed equally to this work. 
abnormal development ${ }^{(2,14,15)}$. It has also been observed that folate supplementation can enhance the immunity of domestic animals $^{(16-18)}$. However, although folate is fundamental for embryonic and fetal development, whether IOF of folic acid can influence the growth performance, folate metabolism and immune function of broilers has not been well investigated.

The present experiment was therefore undertaken to evaluate the effects of folic acid injection during incubation on the growth performance and immune function of broilers. Simultaneously, to explore the potential epigenetic mechanisms underlying such effects, we studied the splenic expression of immune effector molecules and determined the status of conformation and histone methylation on their promoters. The information obtained in this study can therefore be useful for understanding the role of folate on growth and immunity adjustment in poultry.

\section{Methods}

\section{Animals and sampling}

Incubation. A total of 400 fertilised broiler (Cobb 500) eggs were selected with an average weight of $65.7 \mathrm{~g}$. Eggs were randomly assigned to four groups $-0,50,100$ and $150 \mu \mathrm{g}$ of folic acid - and each group was uniformly assigned to five incubator trays. The microcomputer automatic incubator (9TV-2A; Beijing LanTianJiao Electronic Technology Co., Ltd) was calibrated before hatching. The inner temperature of the incubator was controlled at $38 \cdot 0-38 \cdot 2^{\circ} \mathrm{C}$ from $\mathrm{d} 1$ to 10 , at $37 \cdot 8-38 \cdot 0^{\circ} \mathrm{C}$ from d 11 to 18 and at $37 \cdot 5-37 \cdot 8^{\circ} \mathrm{C}$ from d 19 to 21 . The humidity was maintained at $45-65 \%$. A $270^{\circ}$ overturn of the eggs was continued for 3 min every 2 h until d19. On d 3 and 10 , all eggs were candled, after which infertile and dead eggs were removed. Levels of folic acid were injected into the yolk sac at embryonic age $11 \mathrm{~d}$, and the injection volume of each egg was $0 \cdot 1 \mathrm{ml}$. The incubation period was $21 \mathrm{~d}$.

The hatchability of fertilised eggs (\%) was calculated as follows: (the number of hatchlings/the number of fertilised eggs) $\times 100$.

Feeding. Each treatment was allocated to six replicates with 12 broilers/replicate after incubation. The composition of the experimental diet is shown in Table 1. All birds were placed in three-layer wired battery cages and housed in an environmentally controlled room maintained at $32-34^{\circ} \mathrm{C}$ for the first week and then reduced by $2-3^{\circ} \mathrm{C} /$ week. The relative humidity was set at $50 \%$ throughout the study, and the lighting programme was $23 \mathrm{~h}$ of light for the first 2 weeks and $20 \mathrm{~h}$ thereafter. Birds were given free access to commercial diet and water. Feeds were offered as pellets in the whole phase, and a disc automatic feeding system was used to avoid feed spillage. The feeding period lasted for $42 \mathrm{~d}$.

Sampling. On d1, 21 and 42, birds were first weighed in bulk, and then one bird approximate to the average body weight (BW) was selected from each replicate and weighed after fasting for $12 \mathrm{~h}$. Blood samples were taken from the wing vein,
Table 1. Ingredients and nutrient composition of broiler diets on fed basis ${ }^{(52)}$

\begin{tabular}{lrr}
\hline Items & $1-21 \mathrm{~d}$ & $22-42 \mathrm{~d}$ \\
\hline Ingredient (\%) & & \\
Maize & $57 \cdot 80$ & 62.80 \\
Soyabean meal (43\% CP) & 34.60 & 29.70 \\
Soyabean oil & 3.00 & 4.00 \\
Limestone & 1.30 & 0.60 \\
Dicalcium phosphate & 1.60 & 1.30 \\
Salt & 0.40 & 0.40 \\
DL-Met & 0.20 & 0.10 \\
L-Lys & 0.10 & 0.10 \\
Premix & 1.00 & 1.00 \\
Calculation of nutrients (\%) & & \\
ME (MJ/kg) & 12.33 & 12.92 \\
CP & 20.70 & 19.00 \\
Ca & 1.00 & 0.85 \\
Available P & 0.44 & 0.40 \\
Total Lys & 1.20 & 1.05 \\
Total Met & 0.50 & 0.38 \\
Total Met + Cys & 0.84 & 0.68 \\
\hline
\end{tabular}

$\mathrm{CP}$, crude protein; $\mathrm{ME}$, metabolisable energy.

* Premix provided per $\mathrm{kg}$ of feed: vitamin $\mathrm{A}, 8000 \mathrm{IU}$; vitamin $\mathrm{D}_{3}, 2500 \mathrm{IU}$; vitamin $\mathrm{K}_{3}$, $2.65 \mathrm{mg}$; vitamin $B_{1}, 2 \mathrm{mg}$; vitamin $B_{2}, 6 \mathrm{mg}$; vitamin $B_{12}, 0.025 \mathrm{mg}$; vitamin $B_{12}$, $0.025 \mathrm{mg}$; vitamin $\mathrm{E}, 30 \mathrm{IU}$; biotin, $0.0325 \mathrm{mg}$; pantothenic acid $12 \mathrm{mg}$; niacin, 50 mg; Cu, 8 mg; Zn, 75 mg; Fe, 80 mg; Mn, 100 mg; Se, 0.15 mg; I, 0.35 mg.

and the plasma samples were obtained by centrifugation at $2500 \mathrm{rpm}$ for $10 \mathrm{~min}$ at $4^{\circ} \mathrm{C}$ and then frozen at $-20^{\circ} \mathrm{C}$ for analysis. After the blood sampling, broilers were electrically stunned and executed by exsanguination and necropsied immediately. Spleen and liver were removed within $15 \mathrm{~min}$ postmortem, snap-frozen in liquid $\mathrm{N}_{2}$ and stored at $-80^{\circ} \mathrm{C}$ until further analysis.

The experimental protocol was in accordance with the Regulations for the Administration of Affairs Concerning Experimental Animals (Ministry of Science and Technology, China, revised 2004) and approved by the Institutional Animal Care and Use Committee (College of Animal Science and Technology, Northwest A\&F University, China).

\section{Measurement of growth performance}

The BW was recorded for each replicate on $\mathrm{d} 1,21$ and 42; concomitantly, the feed intake was recorded. BW, average daily gain (ADG), average daily feed intake (ADFI) and feed conversion ratio (FCR) were then calculated.

\section{Determination of hepatic folate content and plasma lysozyme activity, IgG and IgM concentration}

A microbial method was used to determine the hepatic folate content ${ }^{(19)}$. Briefly, approximately $200 \mathrm{mg}$ of liver tissue was homogenised and diluted to $10 \mathrm{ml}$ with phosphate buffer solution (PBS) ( $0.02 \mathrm{~mol} / 1, \mathrm{pH} \mathrm{7.2)}$ containing $50 \mathrm{mg}$ of ascorbate. An aliquot of $0.2 \mathrm{ml}$ of homogenate was autoclaved with buffer for $25 \mathrm{~min}$, and then $1 \mathrm{ml}$ of chicken pancreas extract $(6 \mathrm{mg} / \mathrm{ml})$ was added (Difco), further diluted to $10 \mathrm{ml}$ with PBS and incubated overnight $\left(37^{\circ} \mathrm{C}\right)$. After centrifugation $(3000 \mathrm{rpm}, 10 \mathrm{~min})$, a further 5-fold dilution was made for the supernatant before addition to the assay tubes. The folate content in the culture medium has a 
direct relationship with the growth and propagation of Lactobacillus casei ATCC 7469, and bacterial multiplication is computed by the optical density (OD) value. After an overnight incubation at $37^{\circ} \mathrm{C}$, the turbidity was measured at $540 \mathrm{~nm}$. The folate contents were calculated and expressed as $\mu \mathrm{g} / \mathrm{g}$ of liver tissue.

The lysozyme activity and the concentration of $\operatorname{IgG}$ and IgM in plasma were measured using commercially available kits (A050-1, E026 and E025, respectively; Nanjing Jiancheng Bioengineering Institute) according to the manufacturer's instructions.

\section{Real-time PCR for mRNA quantification}

The total RNA was extracted from tissue samples using a total RNA extraction kit (9767; Takara) according to the manufacturer's protocol. Total RNA was quantified using the NanoDrop ${ }^{\circledR}$ ND-1000 spectrophotometer (Thermo Scientific) with the OD value at $260 \mathrm{~nm}$, and the purity was assessed by determining the $\mathrm{OD}_{260}: \mathrm{OD}_{280}$ ratio and formaldehyde-agarose gel electrophoresis. The complementary DNA (cDNA) was synthesised with a PrimeScript ${ }^{\circledR}$ RT reagent Kit (Takara) according to the protocols provided by the manufacturer. All cDNA samples were stored at $-20^{\circ} \mathrm{C}$ until use. The gene ( $\beta$-actin, MTHFR, MTRR, IL-2, IL-4 and IL-O) expressions were performed with SYBR $^{\circledR}$ Premix Ex Taq ${ }^{\mathrm{TM}}$ II (RR8R; Takara). Briefly, a $25-\mu$ PCR mixture was prepared as follows: $12.5 \mu \mathrm{l}$ of SYBR $^{\circledR}$ Premix Ex Taq II $(2 \times), 1 \mu$ l of forward primer $(10 \mu \mathrm{M} / \mathrm{l})$, $1 \mu \mathrm{l}$ of reverse primer $(10 \mu \mathrm{m} / \mathrm{l}), 1 \mu \mathrm{l}$ of $\mathrm{cDNA}$ and $9.5 \mu \mathrm{l}$ of double-distilled water. Primers for real-time PCR were synthesised by Sangon Biotech, and they are listed in Table 2. The PCR was conducted on an iCycler iQ5 multicolour real-time PCR detection system (Bio-Rad Laboratories) programmed as follows: $95^{\circ} \mathrm{C}$ for $10 \mathrm{~min}$; 40 cycles of $95^{\circ} \mathrm{C}$ for $10 \mathrm{~s}, 60^{\circ} \mathrm{C}$ for $30 \mathrm{~s}, 72^{\circ} \mathrm{C}$ for $30 \mathrm{~s}$; and $72^{\circ} \mathrm{C}$ for $5 \mathrm{~min}$. All samples were run in triplicate, and the average cycle threshold $\left(C_{t}\right)$ values were used for quantification using the $2^{-\triangle \Delta C_{t}} \operatorname{method}^{(20)}$.

\section{Micrococcal nuclease quantitative PCR assay for promoter conformation}

Briefly, the cell nuclei were extracted from spleen tissue using a nucleus extraction kit (CN1100; Solarbio) first, and then a suitable dose of micrococcal nuclease (MNase) (N3755; Sigma) was selected to digest these cell nuclei. Next, the histone was digested by proteinase K to obtain DNA. Last, the PCR was conducted with a $20-\mu \mathrm{l}$ mixture system containing the following: $10 \mu \mathrm{l}$ of $\mathrm{SYBR}^{\circledR}$ Premix Ex Taq II $(2 \times), 1 \mu \mathrm{l}$ of forward primer $(10 \mu \mathrm{m} / \mathrm{l}), 1 \mu \mathrm{l}$ of reverse primer $(10 \mu \mathrm{m} / \mathrm{l}), 1 \mu \mathrm{l}$ of DNA and $7 \mu \mathrm{l}$ of double-distilled water. The primers used are listed in Table 2 . The PCR cycle conditions were set as follows: $95^{\circ} \mathrm{C}$ for $15 \mathrm{~min}$, followed by 10 cycles of $95^{\circ} \mathrm{C}$ for $15 \mathrm{~s}, 70^{\circ} \mathrm{C}$ for $30 \mathrm{~s}$ and $72^{\circ} \mathrm{C}$ for $45 \mathrm{~s}$, and then followed by another 35 cycles of $94^{\circ} \mathrm{C}$ for $15 \mathrm{~s}, 60^{\circ} \mathrm{C}$ for $30 \mathrm{~s}$ and $72^{\circ} \mathrm{C}$ for $45 \mathrm{~s}$. All samples were run in triplicate, and the analytical method used for MNase-quantitative PCR data was previously reported ${ }^{(21,22)}$.

\section{Chromatin immunoprecipitation assay for histone methylation}

DNA combined with the dimethylation of histone $\mathrm{H} 3$ lysine 4 (H3K4me2) or H3K9me2 was prepared using the EpiQuik ${ }^{\mathrm{TM}}$ Tissue Methyl-Histone H3K4 (H3K9) chromatin immunoprecipitation (ChIP) kit (P2009 and P2008, respectively; Epigentek). Next, quantitative PCR was performed to determine the accessibility to promoters of genes ( $I L-2, I L-4$ and $I L-G)$. A reaction system $(25 \mu \mathrm{l})$ was as follows: Quantitect $(2 \times), 10 \mu \mathrm{l}$; primer mix $(5 \mu \mathrm{m} / \mathrm{l}), 2 \mu \mathrm{l}$; DNA, $2 \mu \mathrm{l}$; and double-distilled water, $11 \mu \mathrm{l}$. Primer sequences used were all obtained from GenBank and are listed in Table 2 . The reaction protocol was as follows: $95^{\circ} \mathrm{C}$ for $15 \mathrm{~min}$, followed by 10 cycles of $95^{\circ} \mathrm{C}$ for $15 \mathrm{~s}, 70^{\circ} \mathrm{C}$ for $30 \mathrm{~s}$ and $72^{\circ} \mathrm{C}$ for $45 \mathrm{~s}$, followed by another 35 cycles of $94^{\circ} \mathrm{C}$ for $15 \mathrm{~s}, 60^{\circ} \mathrm{C}$ for $30 \mathrm{~s}$ and $72^{\circ} \mathrm{C}$ for $45 \mathrm{~s}$. All samples were run in triplicate, and a fold enrichment method (http://www.lifetechnologies.com/) was used to analyse the ChIP-qPCR data.

Table 2. Primer sequences for quantitative real-time PCR analysis

\begin{tabular}{|c|c|c|c|}
\hline Genes & Accession number & Primer sequence $\left(5^{\prime}-3^{\prime}\right)$ & Product size (bp) \\
\hline$\beta$-Actin & NM_205518 & $\begin{array}{l}\text { F: ATTGTCCACCGCAAATGCTTC } \\
\text { R: AAATAAAGCCATGCCAATCTCGTC }\end{array}$ & 113 \\
\hline \multicolumn{4}{|c|}{ For RT-PCR } \\
\hline MTHFR & XM_417645.3 & $\begin{array}{l}\text { F: CGAACCCATCAAGGATAACGA } \\
\text { R: TCAGTAGTAGCCACTTCCCGATT }\end{array}$ & 141 \\
\hline MTRR & XM_004935130.1 & $\begin{array}{l}\text { F: TTCATTCTAACCTGGTGTCTGGA } \\
\text { R: CATTCTACAAGGGCTCGCAAA }\end{array}$ & 71 \\
\hline IL-2 & NW_003763741.1 & $\begin{array}{l}\text { F: GCTAATGACTACAGCTTATGGAGCA } \\
\text { R: TGGGTCTCAGTTGGTGTGTAGAG }\end{array}$ & 138 \\
\hline$I L-4$ & NW_003763914.1 & $\begin{array}{l}\text { F: AACATGCGTCAGCTCCTGAAT } \\
\text { R: TCTGCTAGGAACTTCTCCATTGAA }\end{array}$ & 98 \\
\hline IL-6 & NW_003763664.1 & $\begin{array}{l}\text { F: AAATCCCTCCTCGCCAATCT } \\
\text { R: CCCTCACGGTCTTCTCCATAAA }\end{array}$ & 106 \\
\hline \multicolumn{4}{|c|}{ For MNase-qPCR and ChIP-qPCR } \\
\hline$I L-2$ & NW_003763741.1 & $\begin{array}{l}\text { F: TTCCGAGGTTGGACAGCAC } \\
\text { R: GAGGAAGACTGGGTGGGTGA }\end{array}$ & 211 \\
\hline$I L-4$ & NW_003763914.1 & $\begin{array}{l}\text { F: GAGGCGAGCGATGGAAGC } \\
\text { R: ACAGTGGTAGGAGGCAGATGGT }\end{array}$ & 207 \\
\hline IL-6 & NW_003763664.1 & $\begin{array}{l}\text { F: GGTATTCTGCCTCTTTCCTGA } \\
\text { R: CACCCTGTGATTTCGCCTA }\end{array}$ & 203 \\
\hline
\end{tabular}

MTHFR, methylenetetrahydrofolate reductase; MTRR, methionine synthase reductase; MNase, micrococcal nuclease; ChIP, chromatin immunoprecipitation; qPCR, quantitative PCR. 


\section{Statistical analysis}

The hatchability of fertilised eggs was analysed using binary logistic regression with the SPSS statistical software (version 18.0, SPSS Inc.). All other data were analysed by one-way ANOVA and polynomial regression analysis using the general liners model with the SPSS statistical software (version 18.0). Pearson's correlation analysis test (SPSS statistical software; version 18.0) was used to analyse the relationship between the expression of $I L-2, I L-4$ and $I L-6$ with that of in vivo immune response and epigenetic changes. Significant differences between the treatments were determined using Fisher's least significant difference test. Results were presented as means with their standard errors. Differences in treatment means were considered significant at $P<0.05$, and instances in which $0 \cdot 05<P<0.10$ were considered trends.

\section{Results}

\section{Growth performance}

The hatchabilities of folic acid treatments $(0,50,100$ and $150 \mu \mathrm{g})$ were $79.2,79.4,90.9$ and $89.6 \%$, respectively, and the $\chi^{2}$ value and $P$ value of the logistic model were 9.339 and 0.025 , respectively. Compared with the control group, $50 \mu \mathrm{g}$ of folic acid treatment has no effect $(P=0.971)$ on hatchability, whereas IOF of $100 \mu \mathrm{g}$ of folic acid increased $(P=0.025)$ the hatchability and an increasing trend $(P=0.051)$ was found in the $150-\mu$ g folic acid group.

Although there were no significant differences on ADFI in the different feeding periods, an increasing trend $(P=0.061)$ was observed during $\mathrm{d} 21-42$ with the increased amount of folic acid additive (Table 3). During d21-42 and d1-42, ADG showed an increase $(P<0.05)$ and FCR had a significant decrease $(P<0.05)$ in treatment groups injected with 100 and $150 \mu \mathrm{g}$ of folic acid. It was interesting that the injection of a higher amount of folic acid $(150 \mu \mathrm{g})$ gave rise to an improved BW on $\mathrm{d} 21(P<0.05)$, which was not observed on $\mathrm{d} 42$.

\section{Folate content in the liver}

Compared with the control group, in ovo injection of 50, 100 and $150 \mu \mathrm{g}$ of folic acid all increased the hepatic content of folate on $\mathrm{d} 21(P<0.05)$, and an increase was also observed in the 100 - and $150-\mu \mathrm{g}$ groups on $\mathrm{d} 42(P<0.05)$ (Table 4$)$.

\section{Hepatic expression of methylenetetrahydrofolate reductase and methionine synthase reductase}

The expression of MTHFR was greater in the 150- $\mu$ g group on $\mathrm{d} 1$ and 42 and in the $50-\mu \mathrm{g}$ group on $\mathrm{d} 1 \quad(P<0.05)$

Table 3. Effect of in ovo feeding (IOF) of folic acid on the performance of broilers

(Mean values with their standard errors)

\begin{tabular}{|c|c|c|c|c|c|c|c|c|c|c|c|}
\hline \multirow[b]{3}{*}{ Items } & \multirow[b]{3}{*}{ Days of age } & \multicolumn{8}{|c|}{ Folic acid $(\mu \mathrm{g})$} & & \\
\hline & & \multicolumn{2}{|c|}{0} & \multicolumn{2}{|c|}{50} & \multicolumn{2}{|c|}{100} & \multicolumn{2}{|c|}{150} & \multicolumn{2}{|c|}{$P$} \\
\hline & & Mean & SEM & Mean & SEM & Mean & SEM & Mean & SEM & $P_{A}$ & $P_{L}$ \\
\hline \multirow[t]{3}{*}{$\mathrm{BW} / \mathrm{g}$} & 1 & $42 \cdot 9$ & 0.84 & $44 \cdot 7$ & 1.31 & 43.4 & 0.57 & $44 \cdot 3$ & 0.62 & 0.794 & 0.121 \\
\hline & 21 & $589 \cdot 7^{b}$ & 11.33 & $585 \cdot 0^{b}$ & $15 \cdot 53$ & $600 \cdot 8^{b}$ & $16 \cdot 65$ & $630 \cdot 6^{\mathrm{a}}$ & $8 \cdot 22$ & 0.015 & $<0.001$ \\
\hline & 42 & $1821 \cdot 4$ & 33.35 & $1846 \cdot 0$ & 43.54 & $1865 \cdot 6$ & 19.79 & $1867 \cdot 0$ & 35.57 & 0.378 & 0.009 \\
\hline \multirow[t]{3}{*}{$\mathrm{ADFl} / \mathrm{g}$} & $1-21$ & $38 \cdot 70$ & 0.195 & 37.69 & 0.595 & $39 \cdot 21$ & 0.701 & $40 \cdot 05$ & 0.772 & 0.133 & $<0.001$ \\
\hline & $21-42$ & 93.05 & 1.291 & 99.00 & 3.880 & $100 \cdot 03$ & 4.005 & 108.81 & $5 \cdot 011$ & 0.061 & $<0.001$ \\
\hline & $1-42$ & $61 \cdot 37$ & $1 \cdot 105$ & $64 \cdot 14$ & 0.875 & $64 \cdot 87$ & $1 \cdot 316$ & $67 \cdot 61$ & $2 \cdot 011$ & $0 \cdot 103$ & $<0.001$ \\
\hline \multirow[t]{3}{*}{$\mathrm{ADG} / \mathrm{g}$} & $1-21$ & $30 \cdot 14$ & 0.583 & $30 \cdot 61$ & 0.333 & $29 \cdot 72$ & 0.325 & $31 \cdot 26$ & 0.171 & 0.608 & $<0.001$ \\
\hline & $21-42$ & $56 \cdot 38^{\mathrm{b}}$ & $2 \cdot 714$ & $55 \cdot 13^{b}$ & $2 \cdot 135$ & $58 \cdot 31^{a, b}$ & 2.855 & $63.46^{\mathrm{a}}$ & 1.571 & 0.039 & $<0.001$ \\
\hline & $1-42$ & $43 \cdot 47^{b}$ & 0.150 & $42 \cdot 97^{\mathrm{b}}$ & 0.980 & $46.05^{a}$ & 1.413 & $49.09^{a}$ & 0.724 & 0.018 & $<0.001$ \\
\hline \multirow[t]{3}{*}{ FCR } & $1-21$ & 1.35 & 0.021 & 1.39 & 0.015 & 1.37 & 0.020 & 1.33 & 0.056 & 0.308 & 0.270 \\
\hline & $21-42$ & $2 \cdot 30^{\mathrm{a}}$ & 0.052 & $2 \cdot 33^{a}$ & 0.038 & $2 \cdot 09^{a, b}$ & 0.041 & $1.91^{\mathrm{b}}$ & 0.099 & 0.021 & $<0.0001$ \\
\hline & $1-42$ & $1.98^{\mathrm{a}}$ & 0.038 & $1.97^{\mathrm{a}}$ & 0.052 & $1.79^{\mathrm{b}}$ & 0.095 & $1.85^{\mathrm{b}}$ & 0.022 & 0.014 & $<0.001$ \\
\hline
\end{tabular}

$P_{A}, P$ value of one-way ANOVA; $P_{L}, P$ value of linear analysis; BW, body weight; ADFI, average daily feed intake; ADG, average daily gain; FCR, feed conversion ratio. a,b Mean values $(n 6)$ within a row with unlike superscript letters were significantly different $(P<0.05)$.

Table 4. Effects of in ovo feeding (IOF) of folic acid on folate content in liver of broilers $(\mu \mathrm{g} / \mathrm{g})$

(Mean values with their standard errors)

\begin{tabular}{|c|c|c|c|c|c|c|c|c|c|c|}
\hline \multirow[b]{3}{*}{ Days of age } & \multicolumn{8}{|c|}{ Folic acid $(\mu \mathrm{g})$} & & \\
\hline & \multicolumn{2}{|c|}{0} & \multicolumn{2}{|c|}{50} & \multicolumn{2}{|c|}{100} & \multicolumn{2}{|c|}{150} & \multicolumn{2}{|c|}{$P$} \\
\hline & Mean & SEM & Mean & SEM & Mean & SEM & Mean & SEM & $P_{A}$ & $P_{L}$ \\
\hline 1 & 47.96 & $3 \cdot 413$ & 49.87 & $2 \cdot 278$ & 54.44 & $4 \cdot 183$ & $50 \cdot 23$ & $5 \cdot 268$ & 0.102 & 0.046 \\
\hline 21 & $52.06^{\mathrm{b}}$ & $9 \cdot 827$ & $76 \cdot 21^{a}$ & 5.009 & $82 \cdot 67^{a}$ & 2.399 & $76 \cdot 38^{a}$ & $4 \cdot 113$ & 0.030 & $<0.001$ \\
\hline 42 & $6 \cdot 13^{b}$ & 0.671 & $5.95^{b}$ & 0.708 & $7 \cdot 93^{a}$ & 0.168 & $8 \cdot 20^{a}$ & 0.284 & 0.027 & $<0.001$ \\
\hline
\end{tabular}

$P_{A}, P$ value of one-way ANOVA; $P_{L}, P$ value of linear analysis.

${ }^{a, b}$ Mean values $(n 6)$ within a row with unlike superscript letters were significantly different $(P<0.05)$. 
(A)

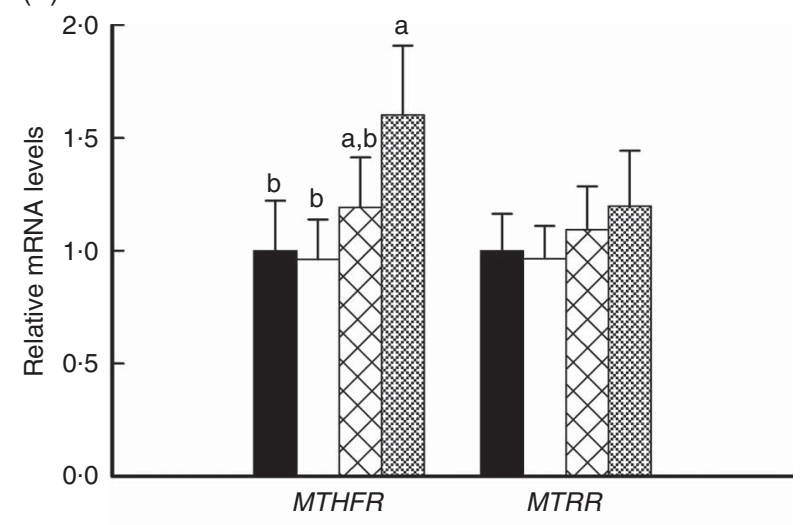

(B)

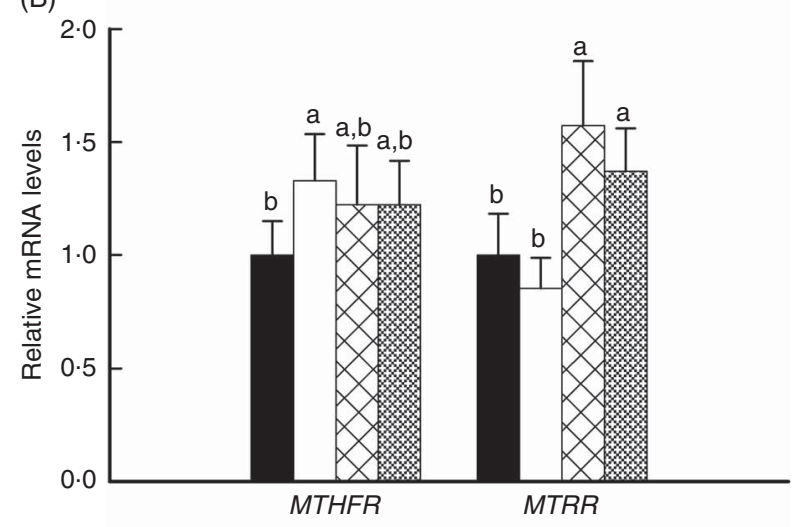

(C)

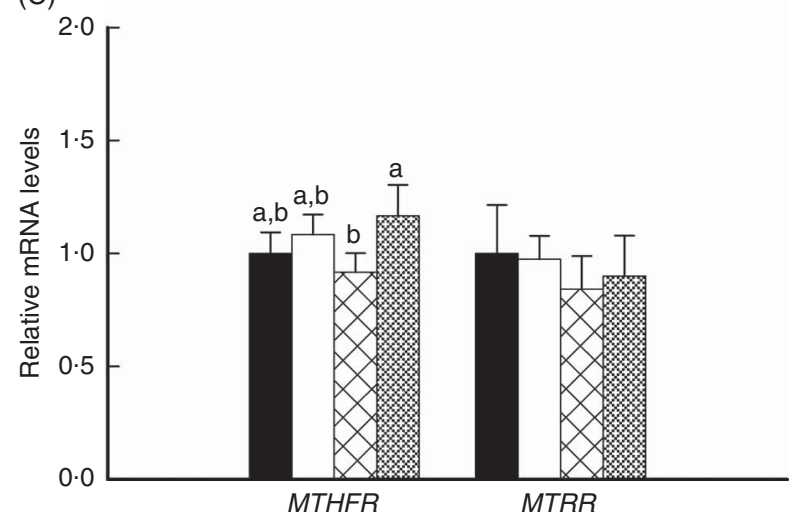

Fig. 1. Effects of in ovo feeding of folic acid on the expression of MTHFR and MTRR on d1 (A), d21 (B) and d42 (C) in livers of broilers. Values are means $(n 6)$, with standard errors represented by vertical bars. Mean values with unlike superscript letters were significantly different $(P<0.05)$. The $P$ values gained by linear analysis $\left(P_{A}\right)$ of MTHFR on d1, 21 and 42 were $<0.001,0.171$ and 0.253 , respectively. The $P_{A}$ values of MTRR on d1, 21 and 42 were $0.096,<0.001$ and 0.275 , respectively. MTHFR, methylenetetrahydrofolate reductase; MTRR, methionine synthase reductase. $\square, 0 \mathrm{mg} ; \square, 50 \mathrm{mg} ; \bigotimes$, $100 \mathrm{mg}$; 圈, $150 \mathrm{mg}$.

(Fig. 1(a), (b) and (c)), and the mRNA expression level of MTRR exhibited a significant increase in the 100- and $150-\mu \mathrm{g}$ treatments on $\mathrm{d} 21(P<0.05)$ (Fig. 1(b)). However, no differences were found in the expression of MTHFR and MTRR on the other days $(P>0 \cdot 05)$.
Lysozyme activity, and the concentration of $\lg G$ and $\lg M$ in plasma

The lysozyme activity in plasma exhibited an increase $(P<0.05)$ with increasing folic acid concentrations on $\mathrm{d} 1,21$ and 42 (Table 5). Compared with the saline group, the $\operatorname{IgG}$ concentration was substantially improved $(P<0 \cdot 01)$ in the 100 and 150- $\mu$ g folic acid groups on d1, 21 and 42. Similarly, on d21 and 42 , folate treatments $(50,100$ and $150 \mu \mathrm{g})$ all showed an increase $(P<0.05)$ in the plasma content of IgM; however, no effect was found on $\mathrm{d} 1$.

\section{Expression of IL-2, IL-4 and IL-6 in the spleen}

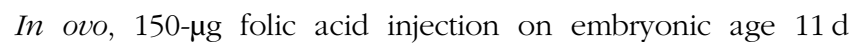
increased $(P<0.05)$ the expression of $I L-2$ while decreasing $(P<0.05)$ the expression of $I L-6$ on $\mathrm{d} 21$ and 42 (Fig. 2(b) and (c)) in the spleen. The expression of $I L-4$ exhibited an increase $(P<0.05)$ in the $100-$ and $150-\mu$ g folic acid treatment groups (Fig. 2(a), (b) and (c)).

\section{Chromatin immunoprecipitation quantitative $P C R$ for the histone methylation of IL-2, IL-4 and IL-6 promoters in the spleen}

On both $\mathrm{d} 21$ and 42, more enriched H3K4me2 mark $(P<0.05$; Fig. 3(a)) was detected in the $I L-2$ promoter in the spleens of broilers hatched to $150-\mu \mathrm{g}$ folic acid-injected eggs. Meanwhile, in ovo, 100- and 150- $\mu$ g folic acid injections resulted in an enrichment $(P<0.05$; Fig. 3(b)) of H3K4me2 mark in the $I L-4$ promoter. In contrast, the levels of $\mathrm{H} 3 \mathrm{~K} 4 \mathrm{me} 2$ in the $I L-6$ promoter exhibited a decrease $(P<0.05$; Fig. $3(\mathrm{c}))$ on both $\mathrm{d} 21$ and 42 in groups supplemented with 100 and $150 \mu \mathrm{g}$ of folic acid. Compared with the saline group, all of the folic acid groups, except 50- and 100- $\mu$ g groups on $\mathrm{d} 21$, showed a decrease $(P<0.05$; Fig. 4(a)) of H3K9me2 mark in $I L-2$ promoters. All of the folic acid groups showed a decrease $(P<0.05$; Fig. $4(\mathrm{~b}))$ of H3K9me2 mark in $I L-4$ promoters. In contrast, the enrichment of $\mathrm{H} 3 \mathrm{~K} 9 \mathrm{me} 2$ in the $I L-6$ promoter exhibited a pronounced increase $(P<0.05$; Fig. 4(c)) with the IOF of folic acid on d21 and 42.

\section{Micrococcal nuclease quantitative PCR for IL-2, IL-4 and IL-6 promoters in the spleen}

Folic acid injection during incubation had no effect on the promoter conformation of $I L-6$ on $\mathrm{d} 21$ and 42 (Fig. 5(c)). As shown in Fig. 5(a) and 5(b), however, the tightness of the $I L-2$ and $I L-4$ promoter conformation was improved $(P<0.05)$ in the $150-\mu$ g treatment group on $\mathrm{d} 21$ and 42 .

\section{Polynomial regression analysis}

The results of polynomial regression analysis indicated that all of the testing indexes, except $I L-2$ and $I L-4$ mRNA expression on d1, MTHFR mRNA expression on d21 and 42, MTRR mRNA expression on $\mathrm{d} 1$ and $42, \mathrm{BW}$ on $\mathrm{d} 1$ and RCR during $\mathrm{d} 1-21$, showed a linear change $(P<0.05)$ with the increased amount of folic acid additive. 
Table 5. Effects of in ovo feeding of folic acid on plasma parameters of broilers (Mean values with their standard errors)

\begin{tabular}{|c|c|c|c|c|c|c|c|c|c|c|c|}
\hline \multirow[b]{3}{*}{ Items } & \multirow[b]{3}{*}{ Days of age } & \multicolumn{8}{|c|}{ Folic acid $(\mu \mathrm{g})$} & & \\
\hline & & \multicolumn{2}{|c|}{0} & \multicolumn{2}{|c|}{50} & \multicolumn{2}{|c|}{100} & \multicolumn{2}{|c|}{150} & \multicolumn{2}{|c|}{$P$} \\
\hline & & Mean & SEM & Mean & SEM & Mean & SEM & Mean & SEM & $P_{A}$ & $P_{L}$ \\
\hline \multirow[t]{3}{*}{ Lysozyme activity (U/ml) } & 1 & $0.36^{c}$ & 0.025 & $0.91^{b}$ & 0.043 & $1.03^{a}$ & 0.013 & $1.04^{a}$ & 0.085 & $<0.001$ & $<0.001$ \\
\hline & 21 & $0.53^{\mathrm{b}}$ & 0.082 & $0.71^{a}$ & 0.010 & $0.81^{a}$ & 0.058 & $0.88^{a}$ & 0.012 & 0.006 & $<0.001$ \\
\hline & 42 & $1.43^{\mathrm{b}}$ & 0.015 & $1.55^{a, b}$ & 0.003 & $1 \cdot 71^{\mathrm{a}}$ & 0.090 & $1 \cdot 73^{\mathrm{a}}$ & 0.042 & 0.010 & $<0.001$ \\
\hline \multirow[t]{3}{*}{$\lg G\left(10^{-4}\right)(g / l)$} & 1 & $0.11^{\mathrm{b}}$ & 0.001 & $0 \cdot 15^{\mathrm{a}}$ & 0.005 & $0 \cdot 16^{\mathrm{a}}$ & 0.003 & $0 \cdot 17^{\mathrm{a}}$ & 0.007 & 0.007 & $<0.001$ \\
\hline & 21 & $0.40^{\mathrm{C}}$ & 0.009 & $0.50^{c}$ & 0.011 & $1.50^{\mathrm{b}}$ & 0.021 & $1.80^{\mathrm{a}}$ & 0.032 & $<0.001$ & $<0.001$ \\
\hline & 42 & $1.50^{\mathrm{C}}$ & 0.029 & $2 \cdot 40^{\mathrm{b}}$ & 0.030 & $2 \cdot 70^{\mathrm{b}}$ & 0.026 & $3 \cdot 30^{\mathrm{a}}$ & 0.046 & $<0.001$ & $<0.001$ \\
\hline \multirow[t]{3}{*}{$\lg M\left(10^{-3}\right)(g / l)$} & 1 & 3.29 & 0.060 & 3.59 & 0.010 & 3.67 & 0.010 & 3.86 & 0.020 & 0.570 & $<0.001$ \\
\hline & 21 & $2 \cdot 75^{\mathrm{c}}$ & 0.015 & $2 \cdot 87^{b}$ & 0.014 & $3 \cdot 25^{\mathrm{a}}$ & 0.017 & $3 \cdot 23^{a}$ & 0.030 & $<0.001$ & $<0.001$ \\
\hline & 42 & $2 \cdot 27^{d}$ & 0.012 & $2 \cdot 41^{\mathrm{C}}$ & 0.021 & $2 \cdot 55^{\mathrm{b}}$ & 0.017 & $2 \cdot 72^{\mathrm{a}}$ & 0.033 & 0.014 & $<0.001$ \\
\hline
\end{tabular}

$P_{A}, P$ value of one-way ANOVA; $P_{L}, P$ value of linear analysis.

a,b Mean values $(n 6)$ within a row with unlike superscript letters were significantly different $(P<0.05)$.

Correlation analysis between the expression levels of IL-2, $I L-4$ and IL-6 with that of in vivo immune response and epigenetic changes

The results of correlation analysis proved that the expression levels of $I L-2$ and $I L-4$ were positively correlated with in vivo immune response (the lysozyme activity and the concentration of $\operatorname{IgG}$ and IgM in plasma), as well as H3K4me2 on their promoters, whereas they were negatively correlated with H3K9me2 and chromatin conformation on their promoters (Table 6). In contrast, the expression of $I L-6$ was negatively correlated with in vivo immune response and $\mathrm{H} 3 \mathrm{~K} 9 \mathrm{me} 2$ and chromatin conformation on its promoter, whereas it was positively correlated with $\mathrm{H} 3 \mathrm{~K} 4 \mathrm{me} 2$ on its promoter (Table 6).

\section{Discussion}

In the present study, IOF of folate caused a significant increase in hepatic expression of MTHFR and MTRR in broilers. MTHFR participates in one-carbon metabolism by converting 5, 10-methylenetetrahydrofolate to 5-methylenetetrahydrofolate, which is the primary circulating form of folate ${ }^{(23,25)}$. In addition, MTRR is essential in maintaining adequate intracellular folate pools. Simultaneously, MTRR participates in catalysing the re-methylation of homocysteine to methionine and is required for the production of SAM ${ }^{(10)}$. These two enzymes both serve as central roles in folate metabolism. Therefore, the incremental expression of MTHFR and MTRR observed in this study indicates that in ovo folic acid supplementation may speed up the circulation of folate in broilers.

Lysozyme, as a nonspecific immunity factor, has an important role in maintaining the physiological equilibrium of organisms through strengthening the phagocytosis of macrophages and leucocytes ${ }^{(26)}$. Similar to lysozyme, Ig is also vital for humoral immunity. The results presented herein demonstrate that, in plasma, at all of the concentrations of lysozyme IgG and IgM exhibited an increase in folic acid-exposed broilers, suggesting that in ovo folic acid supplementation improves the immunity of broilers. In addition, treatment with $1.2 \mathrm{mg}$ of folate daily for
12 weeks was associated with higher levels of proteins (serum albumin, IgM and complement protein) involved in the activation and regulation of immune function in humans ${ }^{(27)}$.

Cytokines, as immune regulatory proteins, have an important role in the immune system ${ }^{(28)}$ as well. Among these proteins, IL-2, produced by $\mathrm{T}$ helper (Th1) cells, regulates cellular immune responses, and IL- 4 , produced by Th2 cells, participates in mediating the humoral immune response ${ }^{(29)}$. IL-6 was originally identified as a B lymphocyte differentiation factor that regulates the immune response, haematopoiesis and inflammation $^{(30)}$. Dietary methyl-donor supplementation has been shown to diminish IL-6 levels in plasma while elevating IL-2 concentrations in mice ${ }^{(16)}$. In agreement with these previous findings, we found a predominant up-regulation of $I L-2$ and $I L-4$ and a pronounced down-regulation of IL- 6 in the spleens of the folate-exposed groups. IL-2 and IL-4 have key roles in antiinflammation, and IL-6 is a pro-inflammatory cytokine. The dynamic balance of anti-inflammation and pro-inflammatory cytokine levels is critical for the health maintenance within animals. Previous researches revealed an attenuated expression of IL-6 in lipopolysaccharide-treated mice ${ }^{(7,31)}$. In addition, the combination of melatonin and folate was reported to reduce the markers of liver injury by $\mathrm{CCl}_{4}$ and the levels of inflammatory cytokines $^{(32)}$. These previous findings are consistent with the effect of folate on immune maintenance and inflammation suppression $^{(17,33)}$, and changes in folate delivery will create substantial differences in gene expression in immune response and human colorectal carcinogenesis ${ }^{(18)}$. Moreover, the results of correlation analysis indicated that the discrepant splenic expression of $I L-2, I L-4$ and $I L-6$ may cooperate with the elevatory plasma concentrations of lysozyme, IgG and IgM on immunity enhancement of folic acid-exposed broilers.

The results presented above only demonstrate the different regulation of immune effector molecules at the transcription level in the spleens of folic acid-exposed broilers. Gene expression and function are also modulated through epigenetic modification ${ }^{(34)}$. Research indicates that maternal dietary exposure can lead to subtle variations in the epigenetic regulation of immune genes expression, which can potentially lead to more profound effects on subsequent immune function, 
Folate supplementation and immune function

(A)

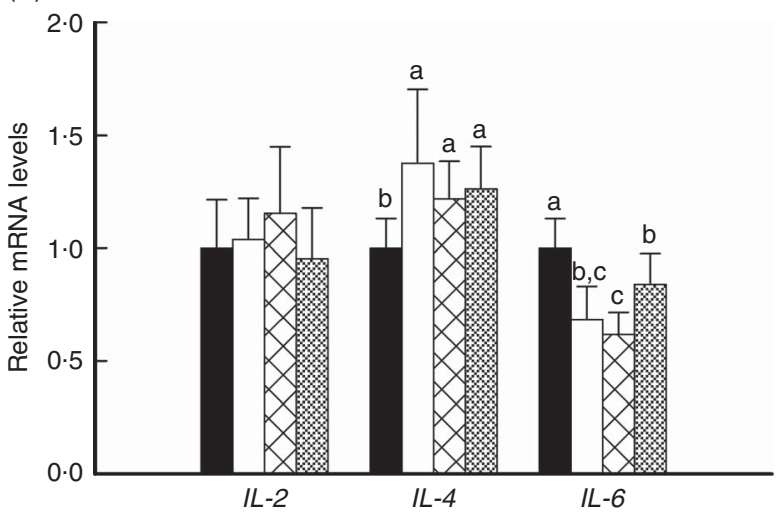

(B)

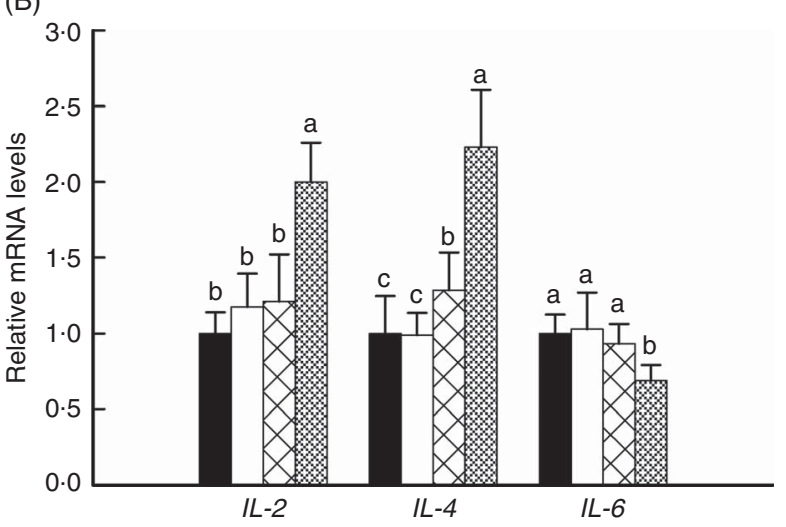

(C)

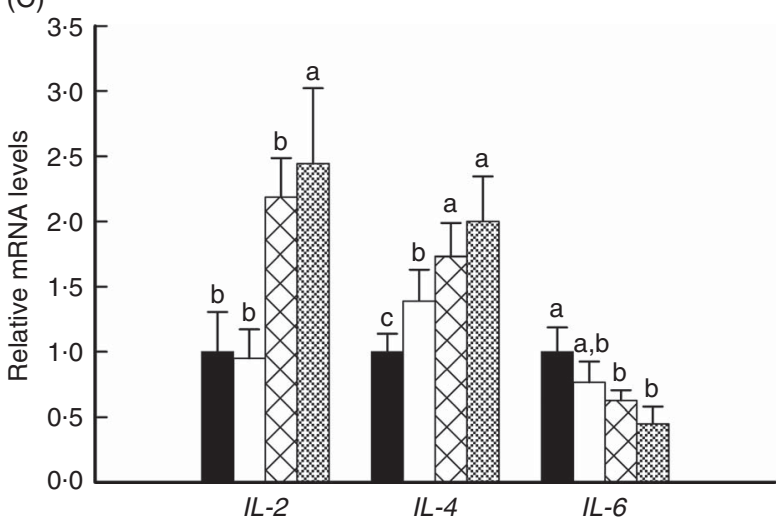

Fig. 2. Effects of in ovo feeding of folic acid on the expression of IL-2, IL-4 and IL-6 on d1 (A), 21 (B) and 42 (C) in spleens of broilers. Values are means $(n 6)$ with standard errors represented by vertical bars. Mean values with unlike superscript letters were significantly different $(P<0.05)$. The $P$ values gained by linear analysis $\left(P_{A}\right)$ of $I L-2$ on d1, 21 and 42 were $0.955,<0.001$ and $<0.001$, respectively. The $P_{A}$ values of $I L-4$ on $d 1,21$ and 42 were $0.177,<0.001$ and $<0.001$, respectively. The $P_{A}$ values of $I L-6$ on $\mathrm{d} 1,21$ and 42 all were 0.036 , $<0.001$ and $<0.001$, respectively., $0 \mathrm{mg} ; \square, 50 \mathrm{mg} ; \otimes, 100 \mathrm{mg}$; 图, $150 \mathrm{mg}$.

clinical phenotype and disease risk ${ }^{(35)}$. Histone modifications are vital mechanisms involved in the transcriptional regulation of genes ${ }^{(36)}$. For instance, H3K4me2 participates in euchromatin formation and ongoing gene expression ${ }^{(37)}$. In the present experiment, higher $\mathrm{H} 3 \mathrm{~K} 4 \mathrm{me} 2$ levels were found on the promoters of $I L-2$ and $I L-4$ in the spleens of broilers exposed to
(A)

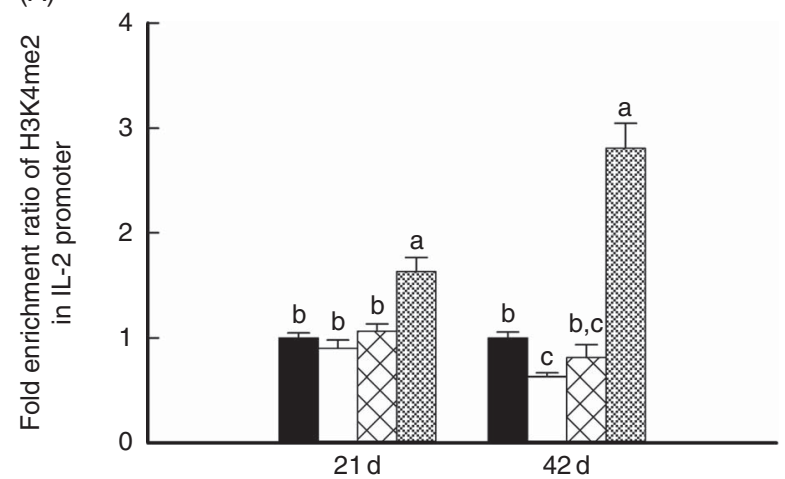

(B)

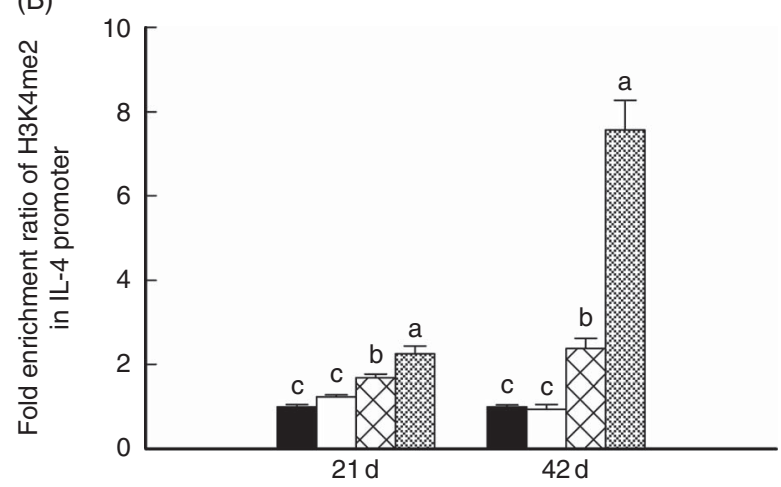

(C)

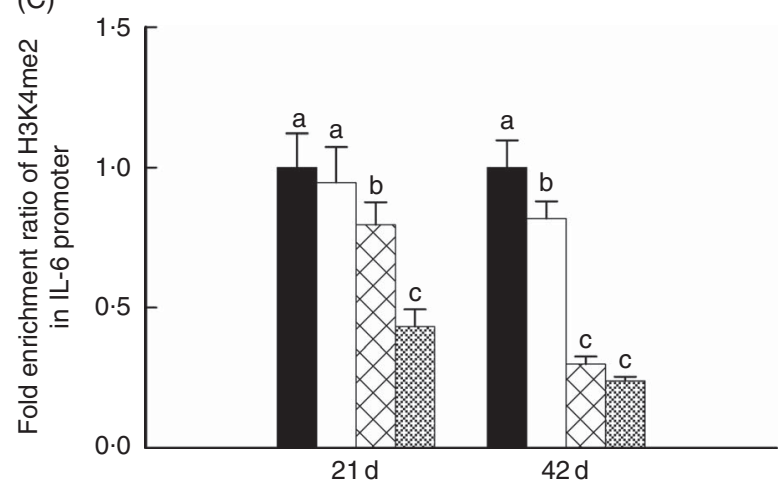

Fig. 3. Effects of in ovo feeding of folic acid on the H3K4me2 enrichment ratio in $I L-2, I L-4$ and $I L-6$ promoters on d1 (A), 21 (B) and 42 (C) in spleens of broilers. Values are means $(n 6)$, with standard errors represented by vertical bars. Mean values with unlike superscript letters were significantly different $(P<0.05)$. The $P$ values gained by linear analysis of $I L-2, I L-4$ and $I L-6$ on d21 and 42 all were $<0.001$. $\mathrm{H} 3 \mathrm{~K} 4 \mathrm{me} 2$, histone $\mathrm{H} 3$ lysine 4 dimethylation., $0 \mathrm{mg}$; $\square, 50 \mathrm{mg} ; \otimes, 100 \mathrm{mg} ;$ 圈, $150 \mathrm{mg}$.

folate, and these levels coincided with the up-regulation of these two genes at the mRNA level; furthermore, the diminished $I L-6$ gene expression was in accordance with less enriched $\mathrm{H} 3 \mathrm{~K} 4 \mathrm{me} 2$ on its promoter. Contrary to $\mathrm{H} 3 \mathrm{~K} 4 \mathrm{me} 2, \mathrm{H} 3 \mathrm{~K} 9 \mathrm{me} 2$ is a repressive histone mark that negatively regulates transcription by promoting a compact chromatin structure ${ }^{(37)}$. The current study, indeed, revealed more enriched $\mathrm{H} 3 \mathrm{~K} 9 \mathrm{me} 2$ on the $I L-6$ promoter. Concomitantly, the decreased H3K9me2 implies the possible involvement of the transcriptional regulation of $I L-2$ and $I L-4$ genes in the spleens of broilers in response to 
(A)

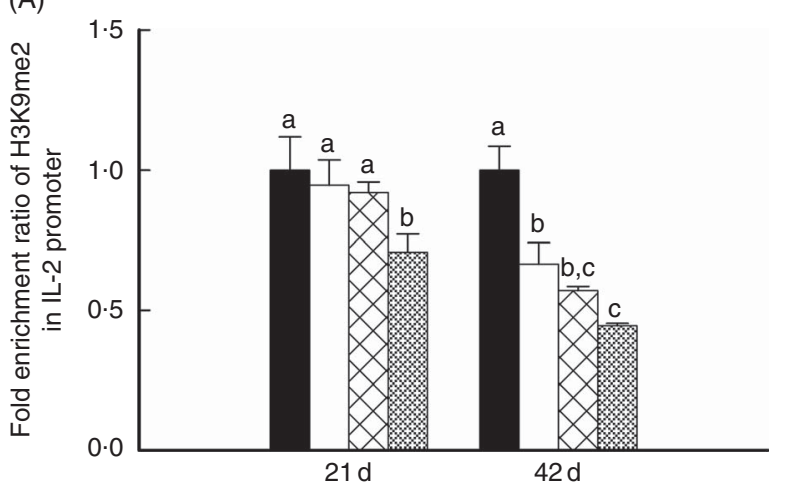

(B)

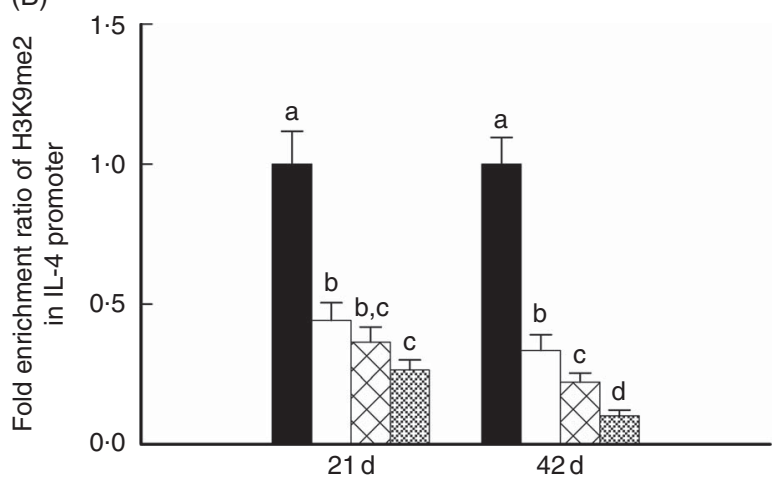

(C)

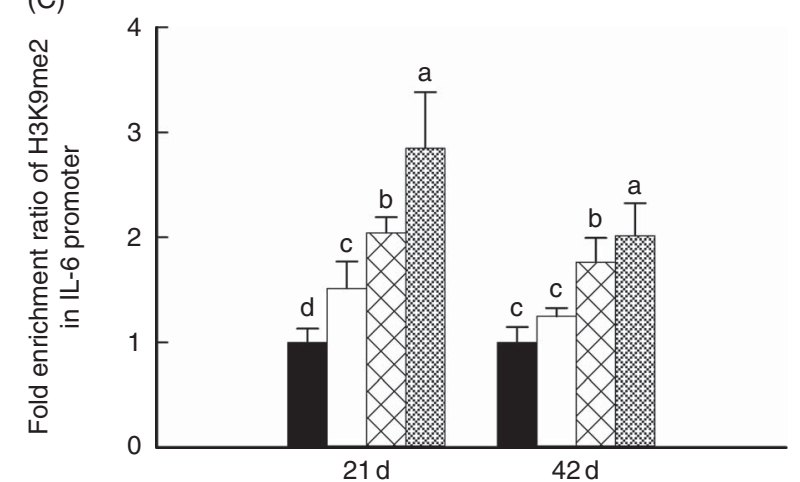

Fig. 4. Effects of in ovo feeding of folic acid on the H3K9me2 enrichment ratio in $I L-2, I L-4$ and $I L-6$ promoters on d1 (A), 21 (B) and 42 (C) in spleens of broilers. Values are means $(n 6)$, with standard errors represented by vertical bars. Mean values with unlike superscript letters were significantly different $(P<0.05)$. The $P$ values gained by linear analysis of $I L-2, I L-4$ and $I L-6$ on day 21 and 42 all were $<0.001$. H3K9me2, histone $\mathrm{H} 3$ lysine 9 dimethylation $0 \mathrm{mg} ; \square, 50 \mathrm{mg} ; \bigotimes, 100 \mathrm{mg}$; 粗, $150 \mathrm{mg}$.

embryonic folate exposure. Therefore, it appears that IOF of folic acid regulates the expression of cytokines by adjusting the histone modification status on their promoters, thus promoting the immune function of broilers.

According to our understanding, the chromatin remodelling caused by the histone modification status of genes' promoters may affect the binding of specific transcriptional factors, thereby regulating the transcriptional levels of these genes ${ }^{(38)}$. Furthermore, the positive regulation of transcription is associated with a more loose promoter conformation with higher
(A)

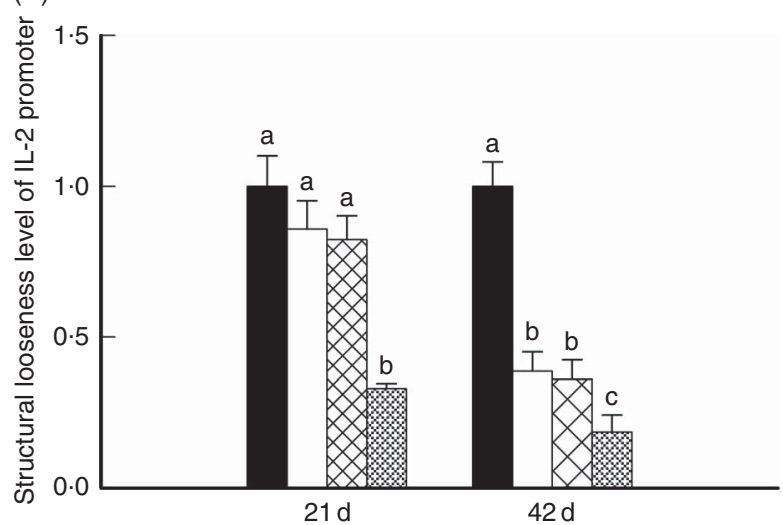

(B)

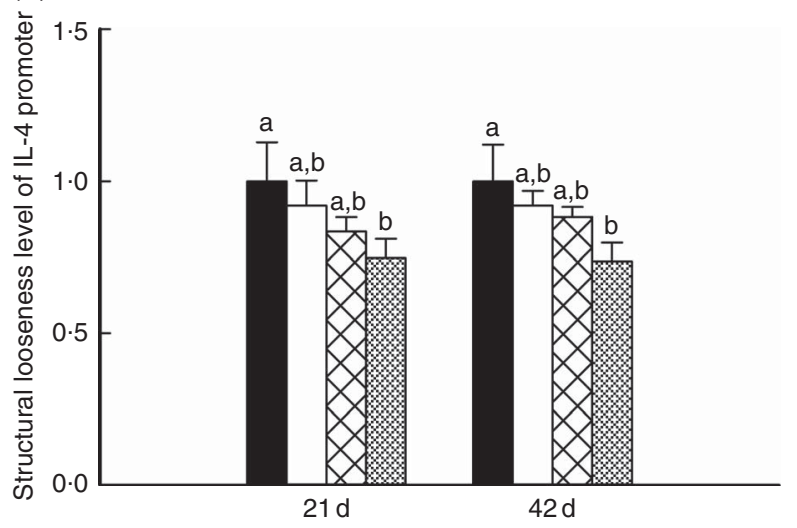

(C)

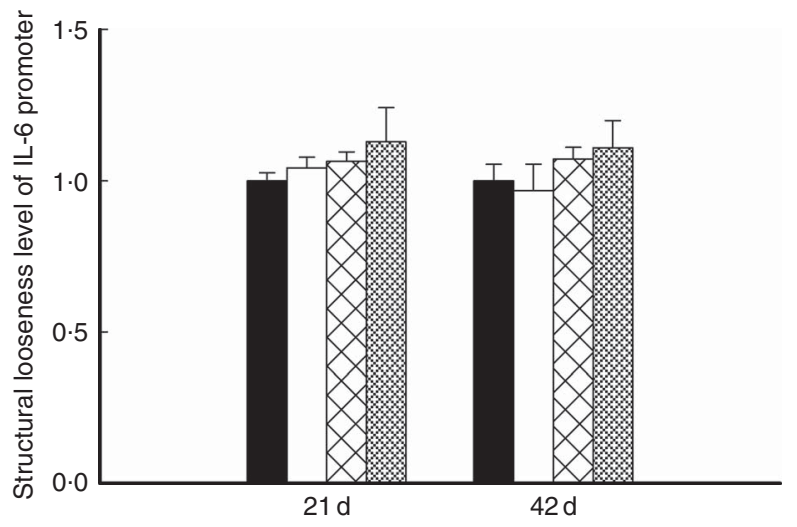

Fig. 5. Effects of in ovo feeding (IOF) of folic acid on chromatin conformation in $I L-2, I L-4$ and IL-6 promoters on d1 (A), 21 (B) and 42 (C) in spleens of broilers. Values are means $(n 6)$, with standard errors represented by vertical bars. Mean values with unlike superscript letters were significantly different $(P<0.05)$. The $P$ values gained by linear analysis of $I L-2, I L-4$ and $I L-6$ on d21 and 42 all were $<0.001 . \square, 0 \mathrm{mg} ; \square, 50 \mathrm{mg} ; \otimes, 100 \mathrm{mg}$; 圈, $150 \mathrm{mg}$.

$\operatorname{accessibility~}^{(39,40)}$, and vice versa. To our surprise, in the current study, we found an incongruity between gene expression and promoter conformation for $I L-2, I L-4$ and $I L-6$. Interestingly, the up-regulation of $I L-2$ and $I L-4$ mRNA expression was accompanied by its reduced promoter accessibilities, which showed a negative correlation. In addition, no differences were found among different treatments on $I L-6$ chromatin conformation. 
Table 6. Correlations between the expression of $I L-2, I L-4$ and $I L-6$ with that of in vivo immune response and epigenetic changes

\begin{tabular}{|c|c|c|c|}
\hline \multirow[b]{2}{*}{ Items } & \multicolumn{3}{|c|}{ Correlations } \\
\hline & $1 d$ & $21 d$ & $42 d$ \\
\hline \multicolumn{4}{|l|}{ IL-2 expression } \\
\hline \multicolumn{4}{|l|}{ In vivo immune response } \\
\hline Lysozyme activity & 0.283 & 0.788 & 0.927 \\
\hline IgG concentration & 0.145 & 0.795 & 0.832 \\
\hline IgM concentration & -0.033 & 0.666 & 0.917 \\
\hline \multicolumn{4}{|l|}{ Epigenetic changes } \\
\hline H3K4me2 & & $0.960^{*}$ & 0.677 \\
\hline H3K9me2 & & $-0.998^{\star \star}$ & -0.795 \\
\hline Promoter conformation & & $-0.998^{\star *}$ & -0.686 \\
\hline \multicolumn{4}{|l|}{ IL-4 expression } \\
\hline \multicolumn{4}{|l|}{ In vivo immune response } \\
\hline Lysozyme activity & 0.819 & 0.763 & $0.980^{*}$ \\
\hline IgG concentration & 0.771 & 0.854 & $0.986^{\star}$ \\
\hline IgM concentration & 0.694 & 0.715 & $0.992^{\star \star}$ \\
\hline \multicolumn{4}{|l|}{ Epigenetic changes } \\
\hline H3K4me2 & & 0.946 & 0.828 \\
\hline H3K9me2 & & -0.611 & -0.930 \\
\hline Promoter conformation & & -0.892 & $-0.956^{\star}$ \\
\hline \multicolumn{4}{|l|}{ IL-6 expression } \\
\hline \multicolumn{4}{|l|}{ In vivo immune response } \\
\hline Lysozyme activity & -0.795 & -0.736 & $-0.963^{\star}$ \\
\hline IgG concentration & -0.682 & -0.857 & $-0.996^{\star \star}$ \\
\hline IgM concentration & -0.520 & -0.712 & $-0.992^{\star \star}$ \\
\hline \multicolumn{4}{|l|}{ Epigenetic changes } \\
\hline H3K4me2 & & $0.984^{*}$ & 0.939 \\
\hline H3K9me2 & & -0.910 & $-0.973^{*}$ \\
\hline Promoter conformation & & -0.922 & -0.812 \\
\hline
\end{tabular}

* Correlation is significant at the 0.05 level (two-tailed).

${ }^{* \star}$ Correlation is significant at the 0.01 level (two-tailed)

Epigenetics is an advanced biological system that selectively uses genomic information and is involved in various fundamental phenomena, among which exist extensive functional interactions ${ }^{(41)}$. Thus, a complex physiological process may be regulated partially or altogether by these mechanisms ${ }^{(42)}$, even leading to an abnormal phenomenon caused by diverse action times and/or action sites, which is beyond our comprehension at first glance. For instance, choline is a methyl donor, but choline-deficient embryos exhibited global and Igf2 DMR2 DNA hypermethylation in a regulatory CpG within the Dnmt1 gene concomitant with the induction of Dnmt1 expression in rats, and the prenatal choline supply increased $I g f 2$ mRNA levels rather than inhibiting gene expression through methyl supply ${ }^{(43)}$.

Obviously, the current study has some limitations. First, folic acid has a vital role in the maintenance of normal patterns of DNA methylation, which is important for cellular homo$\operatorname{eostasis}^{(6,44)}$. The present study did not investigate DNA methylation on related immunogenes. Second, epigenetics is involved in various fundamental phenomena; therefore, further studies are necessary to reveal the internal cause of the incongruity between gene expression and promoter conformation caused by embryonic folate supplementation.

In addition, we also found that IOF of folic acid led to a significant improvement in BW, ADG and FCR at the late growing stage of broilers. Folate is a potential antioxidant with the capacity for oxyradical scavenging ${ }^{(45)}$ and is essential for immunity maintenance ${ }^{(27)}$, and these attributes would help birds cope with more immunological and oxidative stress during the late period. Furthermore, folate has an important role in poultry viability and growth, and folate insufficiency may affect the survival and growth of poultry ${ }^{(46)}$. Therefore, more folate is needed to promote high-intensity growth and overcome more stress in the late stage of broilers.

In the current study, folic acid-exposed eggs also demonstrated a higher hatchability. Researches have shown that the hatchability and poultry weight are associated with folate content in the eggs ${ }^{(47)}$, and higher supplemental folic acid levels may be required for rapid embryonic development ${ }^{(48,49)}$. Although commercial poultry breeder diets contain supplemental folic acid, we do not consider folate as a limiting factor for embryonic development or hatchability, as this inference fails to consider the transport of folate to the $\mathrm{egg}^{(49)}$. IOF can directly convey and deposit nutrients into eggs, avoiding a plateau value of folate levels within the eggs ${ }^{(47)}$. In the present experiment, the concentration of folate in the liver positively responded to increasing levels of IOF folic acid (0-150 $\mu \mathrm{g})$. Moreover, hepatic folate content on d42 showed a greater decrease than that on $\mathrm{d} 1$ and 21 , indicating that folate was efficiently used in the late growing period of birds, and this could be associated with the marked improvement in performance only during the second stage of broilers.

The chicken (Gallus gallus) is an important animal model that bridges the mammals and vertebrates in evolution and has long been used as a model species for the study of embryology, immunology, behaviour and reproduction ${ }^{(50,51)}$. Although mostly descriptive, the results presented herein provide the first evidence that in ovo folic acid injection causes various changes in the splenic expression of immune effector molecules in broilers, with the involvement of epigenetic modifications including histone methylation and chromatin conformation. To some extent, these findings may help in the understanding of the role of embryonic folate supplementation on embryology and immunology in humans.

In summary, in ovo folic acid injection can improve the hatchability and growth performance in the late growth stage of broilers. The increase of hepatic folate concentration, as well as the expression of MTHFR and MTRR, demonstrates the promotion of folate metabolism. IOF of folate also enhances immune function via increasing plasma lysozyme activity and IgG and IgM concentrations, increasing the splenic expression of $I L-2$ and $I L-4$, and down-regulating the expression of $I L-6$, and the differential expression of immune effector molecules can be regulated by the histone modification of $\mathrm{H} 3 \mathrm{~K} 4 \mathrm{me} 2$ and H3K9me2 and chromatin conformation in their promoters. Moreover, within the ranges of this research, the 150- $\mu$ g treatment group was the best considering comprehensively all of the testing indexes.

\section{Acknowledgements}

This study was supported by the Natural Science Foundation of China (No.31272464), the Programme for New Century Excellent Talents (NCET-12-0476) and the Program for Shaanxi Youth Scientific Talents (2012KJXX-18). None of these funders had a role in the design, analysis or writing of this article. 
The authors are grateful to the staff at Animal Nutrition and Feed Science of Northwest A\&F University for their assistance in conducting the experiment.

We express our sincere gratitude to Dr Kai Liu and Dingkui Qin for their suggestions and revisions of the paper.

The authors' contributions are as follows: S. L., L. Z., X. Y. and J. Y. designed the research; S. L., L. Z., Y. L., J. S. and L. L. performed the research and analysed the data; S. L. and L. Z. wrote the manuscript; X. Y. and J. Y. participated in the revision of the manuscript. S. L. and L. Z. contributed equally to this work, and all authors contributed to the data interpretation and approved the final version of the manuscript.

The authors declare that no conflict of interest exists.

\section{References}

1. Reik W, Dean W \& Walter J (2001) Epigenetic reprogramming in mammalian development. Science 293, 1089-1093.

2. Cai D, Jia Y, Lu J, et al. (2014) Maternal dietary betaine supplementation modifies hepatic expression of cholesterol metabolic genes via epigenetic mechanisms in newborn piglets. Br J Nutr 112, 1459-1468.

3. Skinner MK, Haque CG, Nilsson E, et al. (2013) Environmentally induced transgenerational epigenetic reprogramming of primordial germ cells and the subsequent germ line. PLOS ONE 8, e66318.

4. Kornasio R, Halevy O, Kedar O, et al. (2011) Effect of in ovo feeding and its interaction with timing of first feed on glycogen reserves, muscle growth, and body weight. Poult Sci $\mathbf{9 0}$, $1467-1477$.

5. Zhai W, Neuman S, Latour MA, et al. (2008) The effect of in ovo injection of L-carnitine on hatchability of white leghorns. Poult Sci 87, 569-572.

6. Choi S-W \& Mason JB (2002) Folate status: effects on pathways of colorectal carcinogenesis. J Nutr 132, 2413S-2418S.

7. Zhao M, Chen $\mathrm{YH}$, Chen $\mathrm{X}$, et al. (2014) Folic acid supplementation during pregnancy protects against lipopolysaccharide-induced neural tube defects in mice. Toxicol Lett 224, 201-208.

8. Bailey LB \& Gregory JF (1999) Folate metabolism and requirements. J Nutr 129, 779-782.

9. Fox JT \& Stover PJ (2008) Folate-mediated one-carbon metabolism. Vitam Horm 79, 1-44.

10. Sharp L \& Little J (2004) Polymorphisms in genes involved in folate metabolism and colorectal neoplasia: a HuGE review. Am J Epidemiol 159, 423-443.

11. Boushey CJ, Beresford SA, Omenn GS, et al. (1995) A quantitative assessment of plasma homocysteine as a risk factor for vascular disease: probable benefits of increasing folic acid intakes. JAMA 274, 1049-1057.

12. Kalra DK (2004) Homocysteine and cardiovascular disease. Curr Atheroscler Rep 6, 101-106.

13. Thaler R, Nelssen J, Goodband R, et al. (1989) Effect of dietary folic acid supplementation on sow performance through two parities. J Anim Sci 67, 3360-3369.

14. Lillycrop KA, Rodford J, Garratt ES, et al. (2010) Maternal protein restriction with or without folic acid supplementation during pregnancy alters the hepatic transcriptome in adult male rats. Br J Nutr 103, 1711-1719.

15. Weaver IC, Champagne FA, Brown SE, et al. (2005) Reversal of maternal programming of stress responses in adult offspring through methyl supplementation: altering epigenetic marking later in life. J Neurosci 25, 11045-11054
16. Delaney C, Garg SK, Fernandes C, et al. (2013) Maternal diet supplemented with methyl-donors protects against atherosclerosis in F1 ApoE ${ }^{-/-}$mice. PLOS ONE 8, e 56253.

17. Feng D, Zhou Y, Xia M, et al. (2011) Folic acid inhibits lipopolysaccharide-induced inflammatory response in RAW264.7 macrophages by suppressing MAPKs and NFkappaB activation. Inflamm Res 60, 817-822.

18. Protiva P, Mason JB, Liu Z, et al. (2011) Altered folate availability modifies the molecular environment of the human colorectum: implications for colorectal carcinogenesis. Cancer Prev Res (Phila) 4, 530-543.

19. Hoppner K \& Lampi B (1980) Folate levels in human liver from autopsies in Canada. Am J Clin Nutr 33, 862-864.

20. Livak KJ \& Schmittgen TD (2001) Analysis of relative gene expression data using real-time quantitative PCR and the 2(-Delta Delta C(T)) method. Methods 25, 402-408.

21. Ling G \& Waxman DJ (2013) DNase I digestion of isolated nulcei for genome-wide mapping of DNase hypersensitivity sites in chromatin. Gene Regul 977, 21-33.

22. Shu H, Gruissem W \& Hennig L (2013) Measuring Arabidopsis chromatin accessibility using DNase I-polymerase chain reaction and DNase I-chip assays. Plant Physiol 162, 1794-1801.

23. Choe JY, Lee H, Jung HY, et al. (2012) Methylenetetrahydrofolate reductase polymorphisms, C677T and A1298C, are associated with methotrexate-related toxicities in Korean patients with rheumatoid arthritis. Rheumatol Int 32, 1837-1842.

24. Inanir A, Yigit S, Tekcan A, et al. (2013) IL-4 and MTHFR gene polymorphism in rheumatoid arthritis and their effects. Immunol Lett 152, 104-108.

25. Tomita LY, D'Almeida V, Villa LL, et al. (2013) Polymorphisms in genes involved in folate metabolism modify the association of dietary and circulating folate and vitamin $\mathrm{B}_{6}$ with cervical neoplasia. J Nutr 143, 2007-2014.

26. Krusteva E, Hristova S, Damyanov D, et al. (1997) Clinical study of the effect of the preparation DEODAN on leukopenia, induced by cytostatics. Int I Immunopharmacol 19, 487-492

27. Duthie SJ, Horgan G, de Roos B, et al. (2010) Blood folate status and expression of proteins involved in immune function, inflammation, and coagulation: biochemical and proteomic changes in the plasma of humans in response to long-term synthetic folic acid supplementation. J Proteome Res 9, 1941-1950.

28. Wu B, Cui H, Peng X, et al. (2013) Changes of the serum cytokine contents in broilers fed on diets supplemented with nickel chloride. Biol Trace Elem Res 151, 234-239.

29. Scott P (1993) IL-12: initiation cytokine for cell-mediated immunity. Science 260, 496-497.

30. Ishihara K \& Hirano T (2002) IL-6 in autoimmune disease and chronic inflammatory proliferative disease. Cytokine Growth Factor Rev 13, 357-368.

31. Zhao M, Chen Y-H, Dong X-T, et al. (2013) Folic acid protects against lipopolysaccharide-induced preterm delivery and intrauterine growth restriction through its anti-inflammatory effect in mice. PLOS ONE 8, e82713.

32. Ebaid H, Bashandy SA, Alhazza IM, et al. (2013) Folic acid and melatonin ameliorate carbon tetrachloride-induced hepatic injury, oxidative stress and inflammation in rats. Nutr Metab (Lond) 10, 20

33. Gonda TA, Kim YI, Salas MC, et al. (2012) Folic acid increases global DNA methylation and reduces inflammation to prevent Helicobacter-associated gastric cancer in mice. Gastroenterology 142, 824-833 e827.

34. Waterland RA \& Michels KB (2007) Epigenetic epidemiology of the developmental origins hypothesis. Annu Rev Nutr 27, $363-388$ 
35. Hollingsworth JW, Maruoka S, Boon K, et al. (2008) In utero supplementation with methyl donors enhances allergic airway disease in mice. $J$ Clin Invest 118, 3462-3469.

36. Yun M, Wu J, Workman JL, et al. (2011) Readers of histone modifications. Cell Res 21, 564-578.

37. Pekowska A, Benoukraf T, Zacarias-Cabeza J, et al. (2011) $\mathrm{H} 3 \mathrm{~K} 4$ tri-methylation provides an epigenetic signature of active enhancers. EMBO J 30, 4198-4210.

38. Lee N, Erdjument-Bromage H, Tempst P, et al. (2009) The H3K 4 demethylase lid associates with and inhibits histone deacetylase Rpd3. Mol Cell Biol 29, 1401-1410.

39. Beato M \& Eisfeld K (1997) Transcription factor access to chromatin. Nucleic Acids Res 25, 3559-3563.

40. Biddie SC, John S, Sabo PJ, et al. (2011) Transcription factor AP1 potentiates chromatin accessibility and glucocorticoid receptor binding. Mol Cell 43, 145-155.

41. Holliday R (2006) Epigenetics: a historical overview. Epigenetics 1, 76-80.

42. Goldberg AD, Allis CD \& Bernstein E (2007) Epigenetics: a landscape takes shape. Cell 128, 635-638.

43. Kovacheva VP, Mellott TJ, Davison JM, et al. (2007) Gestational choline deficiency causes global and Igf2 gene DNA hypermethylation by up-regulation of Dnmt1 expression. J Biol Chem 282, 31777-31788.
44. Siegfried Z \& Simon I (2010) DNA methylation and gene expression. WIREs Syst Biol Med 2, 362-371.

45. Letelier ME, Jara-Sandoval J, Molina-Berríos A, et al. (2010) Melatonin protects the cytochrome $\mathrm{P} 450$ system through a novel antioxidant mechanism. Chem-Biol Interact 185, 208-214.

46. Lee CD, Belcher LV \& Miller DL (1965) Field observation of folacin deficiency in poults. Avian Dis 9, 504-512.

47. Hebert K, House JD \& Guenter W (2005) Effect of dietary folic acid supplementation on egg folate content and the performance and folate status of two strains of laying hens. Poult Sci 84, 1533-1538.

48. Snetsinger D, Waibel P, Siccardi F, et al. (1963) The effect of vitamin and antibiotic injections on early turkey poult growth and mortality. Poult Sci 42, 538-539.

49. Robel EJ (1993) Evaluation of egg injection of folic acid and effect of supplemental folic acid on hatchability and poult weight. Poult Sci 72, 546-553.

50. Burt D \& Pourquie O (2003) Chicken genome - science nuggets to come soon. Science 300, 1669-1669.

51. Li Q, Li N, Hu X, et al. (2011) Genome-wide mapping of DNA methylation in chicken. PLOS ONE 6, e19428.

52. Subcommittee on Poultry Nutrition, National Research Council (1994) Nutrient Requirements of Poultry: Ninth Revised Edition. Washington, DC: National Academies Press. 